\title{
A Low Cost Efficient Model for Automatic Barricading of Unmanned Railroad Level Crossings
}

\author{
Tanya Tiwari \\ Samsung India Electronics Pvt. \\ Ltd, Plot No 2A, Sector 126 \\ Noida-201304 UP, INDIA
}

\author{
Tanuj Tiwari \\ Deptt. of Computer Sc. \\ University of Texas \\ Dallas Richardson \\ TX 75080 U.S.A.
}

\author{
Sanjay Tiwari \\ SoS in Electronics \\ Pt.Ravishankar Shukla \\ University \\ Raipur(CG)India
}

\begin{abstract}
Safety on the Indian Railways network is the end product of the cohesive fusion of its myriad parts . Railroad related accidents are more serious or deadly than other transportation accidents in terms of severity and death rate etc. The problem of railway accidents is not of safety standards but the execution of standards. Unmanned Level Crossings continue to be a matter of concern for Indian Railways as most of the train mishaps take place in these unmanned level crossings, . There are about 10,000 unmanned railway crossings in the country which account for around 40 per cent of accidents involving the railways. Therefore, Safety at unmanned level crossings is a cause of serious concern for railways and the public transporter is exploring various ways to address the issue.
\end{abstract}

This paper presents a novel concept of an application to improve safety at unmanned level crossings without the burden of a huge infrastructure cost to the railways governing body. A low cost innovative reliable model has been proposed for automatic blockading of unmanned railway level crossings. . It explores too the quest for improved performance, and the need to focus not just on safety, but to contribute to the delivery of a cost-effective, efficient railway as well.

\section{Keywords}

Technology, Level crossing, traffic management, logic gates, innovation

\section{INTRODUCTION}

Railway system is undoubtly the preferred mode for mass transport on high demand corridors in India and lead to making cities more liveable and sustainable. This whole sector is run by government of India and one of the most popular because it's fast, traffic less, cheapest and most convenient mode of passenger transport both for long distance and suburban traffic. Today, Indian Railways carry 15 times more people than their capacity but still the 'Operating Ratio' of Indian Railways is at a decadal low of 96.9 per cent. In addition, Railways have played a significant role in development and growth of industries. Growth of textile industry in Mumbai, jute industry in areas surrounding Kolkata, coal industry in Jharkhand, etc is largely due to the development of railway network in these areas. Railways help in supplying raw materials and other facilities to the factory sites and finished goods to the market. Agriculture also owes its growth to railways to a great extent. Indian Railways plays a dual role of revenue earning as well as meeting the social obligations which are diametrically opposite and difficult to reconcile.
Trains could not run safely without reliable signaling devices. Signaling is required because Trains are guided by the track and hence have to be routed in such a way as to avoid collisions with one another and secondly Trains cannot stop within the distance that the driver can see - they need to have prior warning of the need to slow down and stop ahead. Signaling systems in railway allow the control, supervision and protection of the railway traffic. These systems play an important part in the railway's capacity and availability [1-4]

Since 2012, six of every 10 rail accidents in India have happened because of mistakes by or the negligence of railway staff, according to a study by NITI Aayog. $\mathrm{n}$ the year to 31 March 2017, 66 of 104 consequential rail accidents were attributed to failure of railway staff according to Indian Railways data There are also several other factors which are responsible for increasing number of railway accidents; some outstanding being overaged tracks, wagons, coaches, bridges and signaling system or a rash act by one of the millions of road users, an irresponsible act by a passenger who carries inflammable goods. Added to these are the acts of sabotage .Fig. 1 portray the number of railway accidents due to various factors and train accident statistics [6-7].
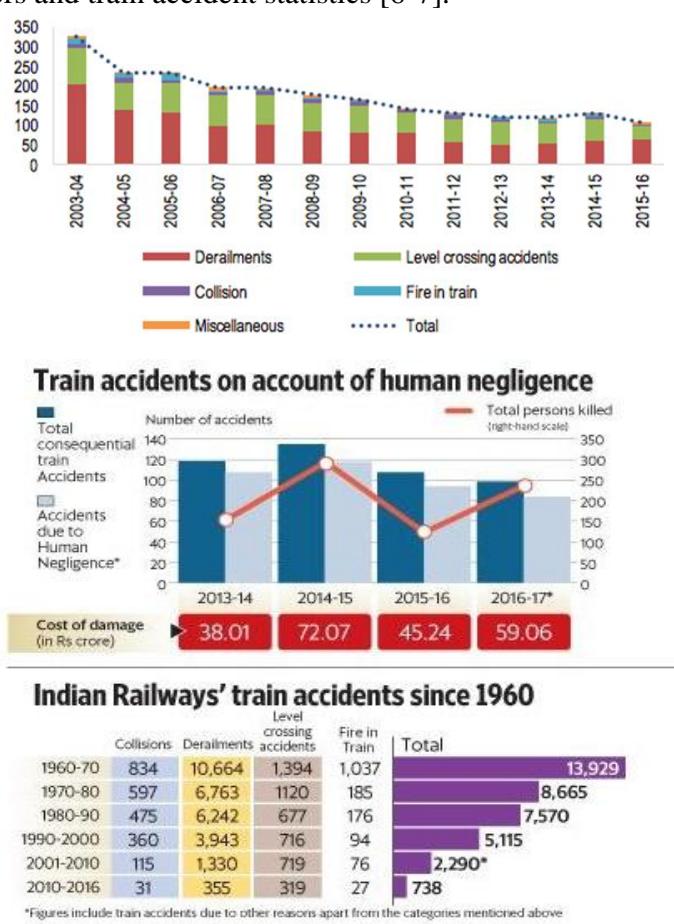

Fig.1 : Number of railway accidents due to various factors and train accident data 
Safety is one of the crucial aspects when it's come to railway operation everywhere. With the ever increasing population, the railway industry always encounters many problems due to technical and human errors, especially at level crossings. The railway level crossing is the one where a railway line and a road intersect with each other at the same level.

Despite the technological advancement and the budgetary expenses made by government on safety of Indian railways, it still struggles in reducing the number of deaths at railway crossings. Train accidents at level crossings have always been a cause of concern for the railways. Quoting The Times of India "40 per cent of consequential accidents and 60 per cent of data of loss of life in train accidents.

The problem is further deeply rooted owing to the presence of unmanned railway crossings. About 10,000 railway crossings are either unmanned or without barriers out of 30,350 accounting about $40 \%$. The scenario of unmanned level crossing is shown in Fig.3.There is always a longing for elimination of accidents by railways. Closure of the railway gates should be made compulsory during passage of train through any railway crossings to avoid causalities. As people casually cross railway crossings within towns and cities at unmanned railway crossings, such incidents do happen on a unmanned railway crossings daily.

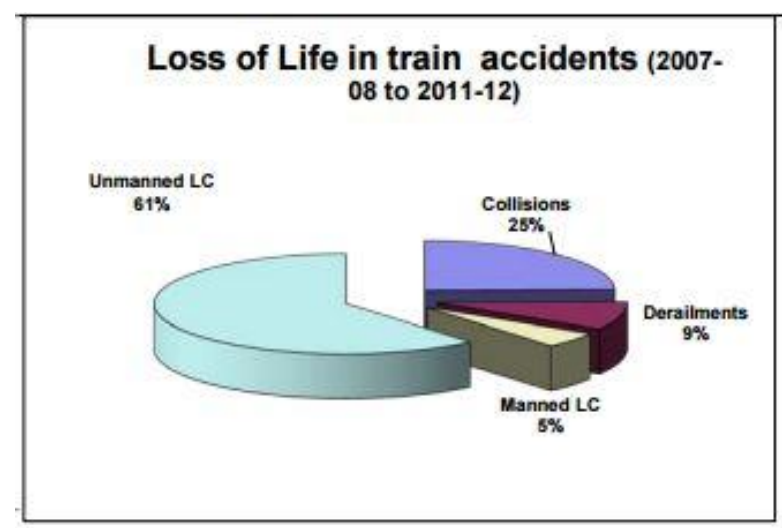

Fig.2 : Death statistics in train accident

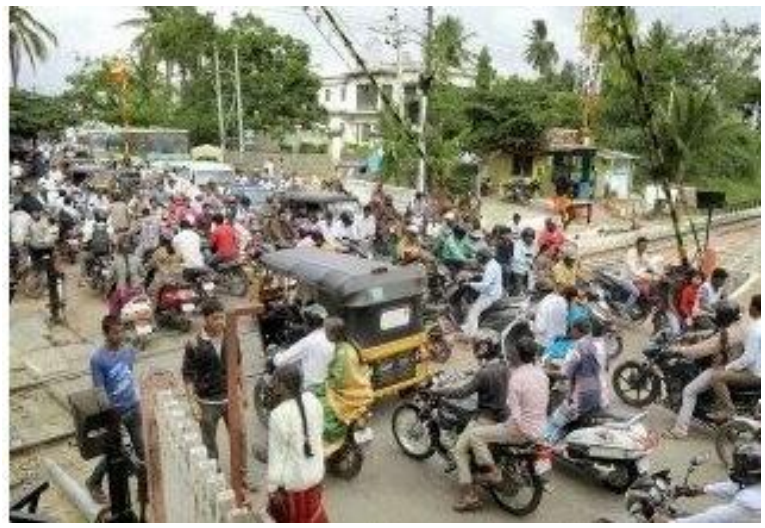

Fig.3 : Unmanned railway crossing

Safety has been one of the biggest concerns in the Indian Railways system. The number of rail accidents has declined from 325 in 2003-04 to 106 in 2015-16. The number of railway accidents divided by cause is shown in the graph below. In 2015-16, majority of the accidents were caused due to derailments $(60 \%)$, followed by accidents at level crossings $(33 \%)$. In the last decade, accidents caused due to both these causes have reduced by about half. it's really difficult in India for implementation of unmanned auto gates with safety due to dense traffic and large population .most of the crossings are being converted to under bridge ways . The unfortunate part is that none will obey automated gates and try to break the rules rather than following it . Better to remain as manual or under bridge .

Divisional railway manager's liaison with the district authorities and the members of parliaments in the selection of unmanned railway crossing for manning. On identification of such railway crossing, Member of Parliament sends his recommendations to the district magistrate/ Dy. Commissioner for releasing funds for capital cost of construction covering the cost of lifting barrier, arrangement of water and electricity, quarters for the gatemen, duty hut etc. Recurring maintenance and operational cost is born by the railways. Based on traffic density, visibility and regular plying of buses/ motor vehicles, unmanned railway crossings have been categorized into following five categories:

\begin{tabular}{|l|l|l|}
\hline S.No. & $\begin{array}{l}\text { Number of train } \\
\text { vehicle units }\end{array}$ & Category \\
\hline 1 & $\begin{array}{l}\text { Railway crossing where the } \\
\text { train vehicle units (TUVs) } \\
\text { exceed 10000 }\end{array}$ & Category- I \\
\hline 2 & $\begin{array}{l}\text { Railway crossing where the } \\
\text { train vehicle units (TUVs) } \\
\text { exceed 6000 and where } \\
\text { visibility is restricted }\end{array}$ & Category- II \\
\hline 3 & $\begin{array}{l}\text { Railway crossing where the } \\
\text { train vehicle units (TUVs) is } \\
\text { less than } 6000 \text { and visibility } \\
\text { is restricted but buses / } \\
\text { motor vehicles ply regularly }\end{array}$ & Category- III \\
\hline 4 & $\begin{array}{l}\text { Railway crossing where the } \\
\text { train vehicle units (TUVs) is } \\
\text { less than } 6000 \text { and visibility } \\
\text { is restricted but buses / } \\
\text { motor vehicles do not ply }\end{array}$ & \\
\hline 5 & $\begin{array}{l}\text { Railway crossing where } \\
\text { visibility is adequate but } \\
\text { traffic density exceed } 6000 \\
\text { train vehicle units (TUVs) }\end{array}$ & \\
\hline
\end{tabular}

Railway is a capital intensive industry. For manned railway crossings and construction of new lines enormous resources are required. Since passenger services are heavily subsidized, surplus resources generated are not adequate to cater to big investments. In such situations an alternative cost effective method should be applied for renewals and replacements.

The railways has set an ambitious target of eliminating all unmanned level crossings on busy routes by 2020 . Unmanned level crossings pose a severe threat to rail safety and are major reasons of train accidents. Currently, the railways has about 4,000 unmanned level crossings on the busy rail corridors across the country. An action plan has been firmed up for eliminating 3,900 unmanned level crossing by 2020 .

Recently Anil Kakodkar Committee has made following recommendations on Railway Safety 
- Need for an independent body like Railway Safety Authority under the government with chairman and experts from outside.

- Complete elimination of both manned and unmanned level crossings within the stipulated time.

Need for advanced signaling system based on continuous track circuiting and cab signaling similar to European train control system Level-II on the entire trunk route of about 19,000 route kilometres.

- Continuous monitoring of all the bridges in terms of scientific measurements of deflections/displacements, water level and flow velocity on a continuous basis and data should be communicated to the office of the concerned Chief Bridge Engineer for monitoring.

- A robust and powerful Safety Architecture should be there to have a safety oversight on the operational mode of Railways.

Looking into budget and technical constraints, it seems difficult to immediately eliminate both manned and unmanned level crossings. The Level crossing is a cross-sectional area where rail track and roadway intersect each other (Figure 4). In most cases, level crossing remains unattended mostly in rural and remote areas. Hence, such intersection requires constant human coordination and monitoring on everyday basis. The level crossing is divided into two type's namely manned and unmanned level crossing. Manned level crossing is further grouped into classes" "A $\mathrm{A}$ "e Class, " $\mathrm{B}$ "c Class and " $\mathrm{C}$ "e Class. On the other hand, unmanned level crossing is grouped into $\mathrm{C}^{\text {ee }}$ Class, $\mathrm{D}^{\text {"e }}$ Class []. Level crossings may be manned or unmanned. One or more gatemen are posted at manned level crossings to regulate the traffic. In an unmanned level crossing, there is no gateman and road users cross the railway line at their own risk after taking the necessary precautions.

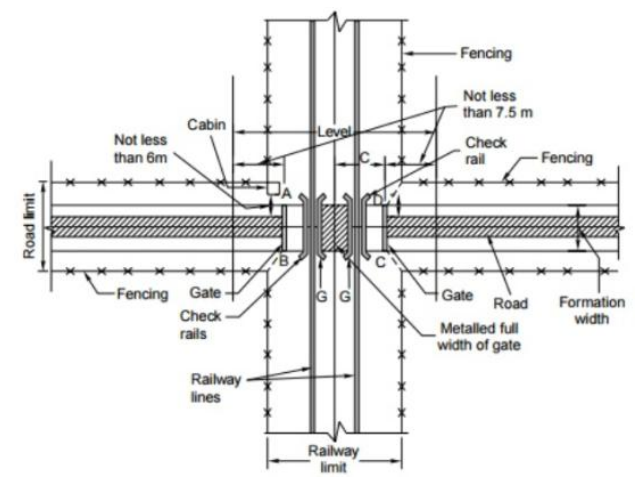

Fig.4 A typical layout of Level crossing.

Furthermore Section 161 in The Railways Act, 1989 states that if any person driving or leading a vehicle is negligent in crossing an unmanned level crossing, he shall be punishable with imprisonment which may extend to one year. But is the fault entirely of roadways users? The error lies in the poor assessment of train speed partly due to the fact that human reaction time is 2.5 seconds giving maximum reflex coordination speed of 60-70 kmph. However trains on Indian railways run at average speed of about $100-120 \mathrm{kmph}$ for which the reaction time is inadequate.

In the past, there are quite a numbers of automated level crossing with advanced technology that were invented to prevent accidents at intersection. To date, studies are still going on to improve safety at level crossing. There are many studies carried out and systems developed based on different technologies to promotion the operation of railway industry without endangering the society.

The recent railway accidents are raising safety concerns in the society as well as in some other part of the world. Accidents can take place anywhere. Even the most advanced technology can't ensure accident free and $100 \%$ safe working conditions. But scientific investigation can be used just to make incremental improvements to a theory, process or the existing system. The occurrence of catastrophes could be reduced by making such investigations to find out the reasons and take necessary actions to avoid recurrence of such incidents. This has inspired many to work on the improvement of the prevailing railway for the betterment of humanity.

Recently it is proposed that Satellite-based chip systems will now alert road users at unmanned level crossings about approaching trains and also help in tracking train movement on a real-time basis. Road users will be warned by hooters once a train approaches an unmanned level crossing as railways are installing ISRO-developed integrated circuit (IC) chips on locomotives of trains. About 500 metres before the level crossings, the hooter will be activated through the IC chip, warning road users as well as the train driver near the crossing. The hooter will be louder as the level crossing nears, and finally it will be silent after the train passes by. There are several other methods proposed for automatically controlled railway gate at the level crossing, railway track switching mechanism and the movement of the train using sensors, micro controllers for reduction of railway accidents but all demand heavy investment [8-20].

Thus a low cost method for automatic barricading of unmanned railroad crossings is a must. This paper will aim at providing one such alternative system.

\section{PROPOSED MODEL}

The proposed system involves four steps:

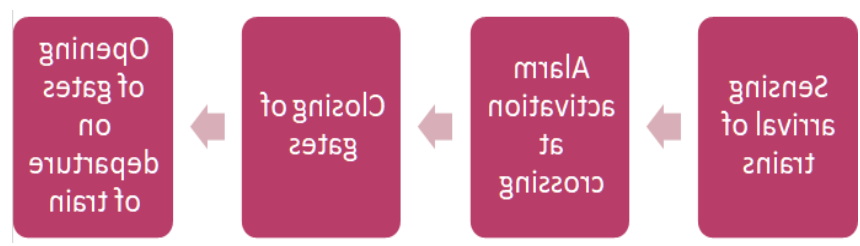

Fig.5: Schematic block diagram of proposed system

Following is the step by step discussion of our model:

\subsection{Sensing arrival of trains}

The mechanism of detection of arrival of train is based on passing of train from tracks few $\mathrm{km}$ away. Owing to the mass of engines, trains exert huge pressure on tracks which can be easily sensed using a spring compression system or piezoelectric materials. This signal needs to be amplified and transmitted to the crossing wirelessly through a low power frequency.

Trains run at maximum speeds of $140 \mathrm{kmh}$ on tracks and assuming closing gates on receiving signal takes 2 minutes with extra precautionary 1 minute mounts to time difference between reception of signal and train passing as 3 minutes.

$140 \mathrm{~km} / \mathrm{h} \times 3 / 60$ hour $=7 \mathrm{~km}$

Therefore the sensors must be positioned $7 \mathrm{~km}$ away from crossings in both directions. 
To make this system more efficient we notice the difference in weights of normal passerby humans, animals and vehicles against the trains. The minimum weight of a locomotive is about 70 tons. Using a spring with constant of values more than $10^{6} \mathrm{~kg} / \mathrm{s}^{2}$ would ensure activation by compression only by objects with mass greater than $10,000 \mathrm{~kg}$.

Furthermore the sensors along with amplifiers need to be connected to transmitters with frequencies of $40 \mathrm{MHz}$ and $50 \mathrm{MHz}$ respectively. Thus on receiving, signal it is transmitted to receivers at crossings without any overlapping of signals.

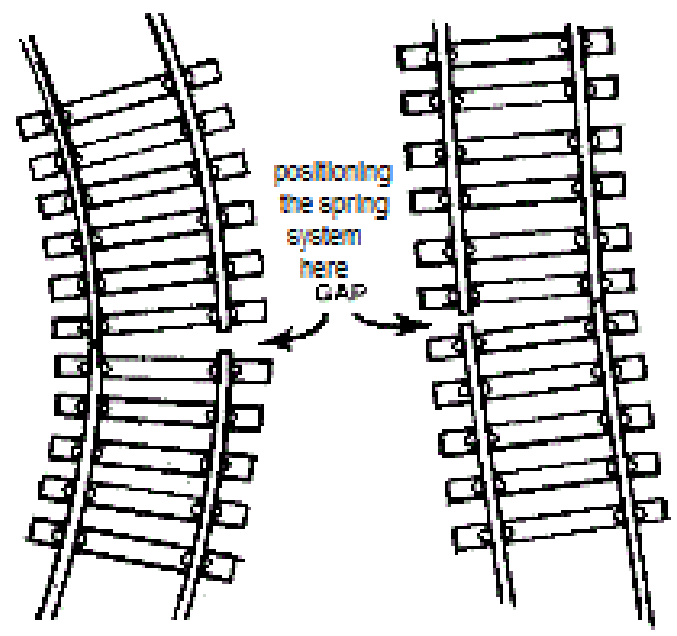

Figure 6 : Positioning of sensors on tracks

\subsection{Activation of alarm at crossing}

Introduction of a receiver at crossing would ensure accurate and timely reception of signals wirelessly. On receiving the signal a counter goes high and the signals from both transmitters are led through series of two gates-OR and EXCLUSIVE OR and AND.

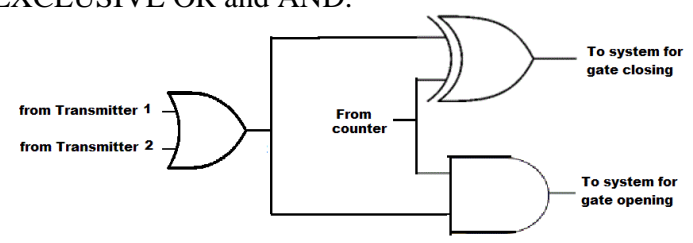

Fig.7 Digital circuitry for alarming system

As soon as Exclusive OR is active an alarm goes off indicating closing of gates

\subsection{Closing of gates}

In place of the electric motor placed in manned crossings, provision of a stepper motor with programmed delay will be more effective. To ensure slow and step by step closing of gates for safety purposes the motor must complete its quarter rotation in 2 minutes. Assuming $9^{\circ}$ in each turn the delay time between each rotation must be $9^{\circ} / 90^{\circ} \times 120 \mathrm{sec}=12$ seconds. It is to be noted that motor moves in the fixed anti clockwise

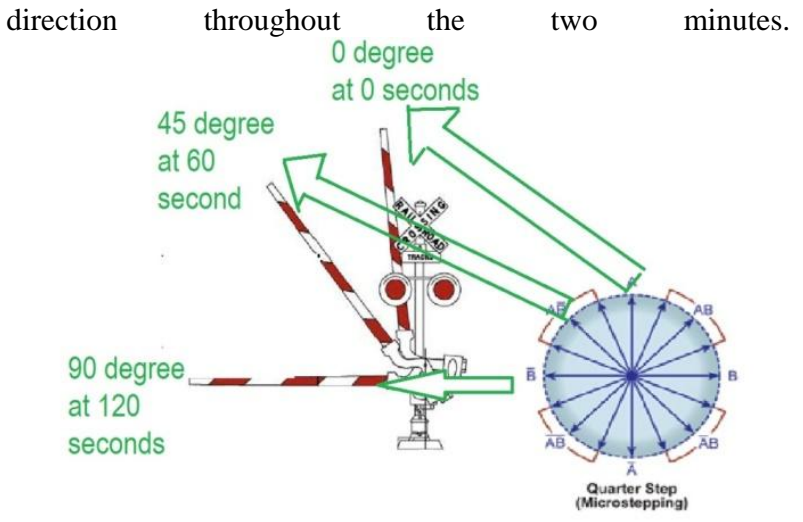

Fig. 8: Working of motor with gate

The specification of gates remains same as that in case of manned crossings. Hence the gates are completely closed 2 minutes after signal reception.

\subsection{Opening of gates after train departure:}

As soon as the train reaches the sensor at the other end sends signal to the transmitter making Exclusive Or inactive and AND active. Thus the process of opening of gates without any delays starts by rotation of motor in clockwise direction for a quarter. As soon as motor is returns to beginning the counter is reset to zero.

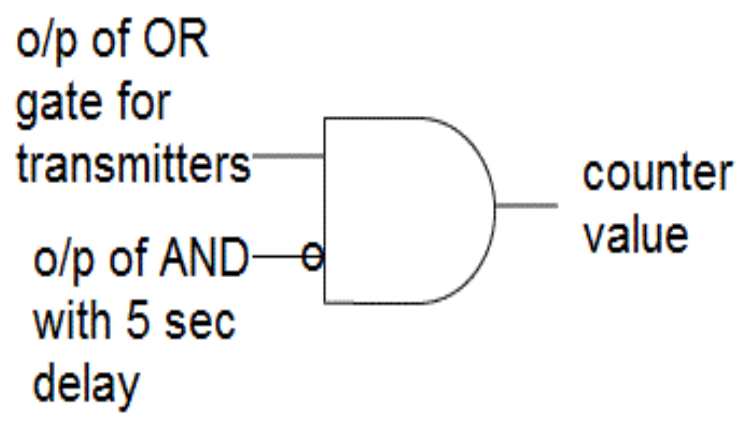

Fig.9: Digital solution for Opening of gates after train departure

Thus as soon as AND leading to opening of gates is activated immediately after 5 seconds counter resets and system comes back to its previous form ready for arrival of next train.

\section{CONCLUSION}

It has been concluded that level crossings of rail and roads pose potential danger to roads users in railway industry. Due to ever increasing number of vehicles daily, it was concluded that using automated technique at level crossing can be useful for the safety of traffic. A low cost innovative and reliable digital system has been proposed for automatic barricading of unmanned railroad crossings. It has been tested and found successful. This system can be used in remote \& rural areas and easy to deploy,

This work is developed in order to support the glory of India, the Indian railways in making its present working system more reliable, by eliminating some of the loopholes existing in it. The automation of the railways is such that it saves energy, provide full safety from the loss of human and materials. So, this type of system can be applied in any railways.

\section{ACKNOWLEDGMENT}

The corresponding author (Tanya) express her sincere gratitude towards Shri Vishwaranjan, Sr D.O.M. ,Shri Harish 
Billore, Sr. D.O.M., and Shri Rakesh Tiwari Chief Controller of DRM Office, West Central Railway, Jabalpur for encouragement, advice and in-depth productive discussions. This paper would not have been possible without his guidance and persistent help.

\section{REFERENCES}

[1] CENELEC: EN 50126 Railways Applications - The Specification And Demonstration Of Reliability, Availability, Maintainability And Safety (RAMS)

[2] CENELEC: EN 50128 Railways Applications: Communications, Signalling And Processing Systems Software For Railway Control And Protection Systems

[3] CENELEC: EN 50129 Railways Applications Communication, Signalling And Processing Systems. Safety Related Electronic Systems For Signalling.

[4] Goundan P.R. And Jhunjhunwala A 1998, "Intermediate Block Signalling (IBS)-A Cost Effective Method To Increase Through Put Of Railways", 48th IEEE Vehicular Technology Conference (VTC98), Ottawa, Canada, Vol. 3, Pp. 2090 - 2094

[5] Vamsi Krishna P., Yugandhar D 2013 , "An Enhanced Railway Transport System Using FPGA Through GPS \& GSM", IJSCE,ISSN: 2231-2307, Vol. 2, Issue 6, Pp. 185-188, January 2013.

[6] Http://Www.Livemint.Com/Politics/Jjcrjn2xbqbaokew7lt t6k

[7] Https://Economictimes.Indiatimes.Com/

[8] Bhattacharya, S. And Debashis, De, 2012 "An Enhanced Handover Strategy For GSM-R Technology", IEEE Third International Conference On Computer And Communication Technology (ICCCT), DOI 10.1109/ICCCT.2012.53, Pp. 227-232.

[9] Hirano Y, Kato T, Kunifuji T, Hattori T. And Kato T, 2005"Development Of Railway Signalling System Based On Network Technology", IEEE International Conference On Systems, Man And Cybernetics,Waikoloa, Vol. 2, Pp. 1353-1358 12.

[10] Thorat S.B., Jagtap S, Murthy R, Pal S And Kalyankar N.V. 2011, Intelligent Computing In Indian Railway Signal Engineering, 6th International Conference On Computer Sciences And Convergence Information Technology (ICCIT), Seogwipo, Pp. 12-17, Nov. 29, 2011-Dec. 1
[11] Morant A, Galar D, Tamarit J. 2012 The Ninth International Conference On Condition Monitoring And Machinery Failure Prevention Technologies 2012 (CM 2012 AND MFPT 2012) Desc:Proceedings Of A Meeting Held 12-14 June 2012, London, UK. ISBN:9781622764334 Pages:1242

[12] Penicka, M 2007 'Formal Approach To Railway Applications', Formal Methods And Hybrid Real-Time Systems', Springer, Pp. 504-520, 2007

[13] "Installation Of The First Network Signal Control System," Press Release By East Japan Railway Company,

Nov7,2006(URL:Http://Www.Jreast.Co.Jp/E/Press/2006 1102/Index.Html).

[14] Sugahara,H.,Kunifuji,T.,Hattori,T.,Hirano,Y.,Fukuta,Y., Matsumoto,M. 2006 "Assurance Technologies For Signal Control System By Optical LAN," IEEE Assurance Conference

[15] Fukuta, Y Kogure,G., Kunifuji, T., Sugahara,H., Ishima,R.,Matsumoto,M. 2007 "Novel Railway Signal Control System Based On The Internet Technology And Its Distributed Control Architecture," IEEE ISADS

[16] Belmonte,F., Berkani,K., Boulanger,J.L.,Schön,W. 2006, 'Safety Enhancement Of Railway Traffic By Modern Supervision Systems', WCRR, Seventh World Congress On Railway Research., Montreal (Canada),

[17] Galar, D, Morant, A.,2012 Integration Of Production Data In CM For Non-Stationary Machinery: A Data Fusion Approach, Condition Monitoring Of Machinery In Non-Stationary Operations', Part 4, Pp 403-414, 2012

[18] Banuchandar, J., Kaliraj,V., Balasubramanian,P., Deepa,S., Thamilarasi, N. 2012 Automated Unmanned Railway Level Crossing System", International Journal Of Modern Engineering Research (IJMER)Volume.2, Issue.1, Pp-458-463.

[19] Mahdi A.S., Zuhairi, Al. 2013 Automatic Railway Gate And Crossing Control Based Sensors \& Microcontroller ", International Journal Of Computer Trends And Technology (IJCTT) - Volume 4 Issue 7-July 2013, Pp.2135-2140.

[20] Kottalil,A.M. Abhijith S, Ajmal M. M., Abhilash L. Ajithbabu,J. 2014 Automatic Railway Gate Control System, International Journal Of Advanced Research In Electrical, Electronics And Instrumentation Engineering, Vol.3,Issue,Pp7619-7622. 